\title{
JURISPRUDENCIA ARGENTINA RECIENTE EN MATERIA DE RIESGOS AMBIENTALES Y RELATIVOS A LA SALUD HUMANA: ARTICULACIONES ENTRE DERECHO DE DAÑOS Y
PRINCIPIO PRECAUTORIO
}

[Recent Argentinean Jurisprudence on Environmental Risks Relating to Human Health: Connections Between the Law Regarding Damages and the Precautionary Principle]

\author{
María Valeria BerRos* \\ Universidad Nacional del Litoral, Argentina
}

\begin{abstract}
Resumen
El trabajo presenta una de las líneas argumentales de la jurisprudencia argentina contemporánea en materia de riesgos ambientales y relativos a la salud humana. Se parte de un conjunto de resoluciones que deciden sobre la exposición a radiaciones no ionizantes y a agroquímicos, que en los últimos años ha sido materia de una notoria judicialización. Este tipo de decisiones se ubican en la intersección entre el derecho de daños, que tradicionalmente en Argentina se ha ocupado del problema de los riesgos, y el principio precautorio que traduce, en el derecho ambiental, la
\end{abstract}

\begin{abstract}
The purpose of this work is to present one of the lines of argument of the contemporaneous Argentinean jurisprudence on environmental risks relating to human health. First, a set of resolutions deciding on the exposure to non-ionizing radiation and to agrochemicals, that over the past years have been turned into a notorious legal issue, are studied. This type of decisions are in the intersection between the law regarding damages that has traditionally dealt, in Argentina, with the risks issue, and the precautionary principle which deals, in the environmental law, with
\end{abstract}

RECIBIDO el 29 de octubre y ACEPTADo el 2 de diciembre de 2014

* Profesora de Derecho civil II e Introducción a la sociología de la Facultad de Ciencias Jurídicas y Sociales de la Universidad Nacional del Litoral. Investigadora Post-doctoral de Conicet. Dirección postal: Centro de Investigaciones en Derecho, Facultad de Ciencias Jurídicas y Sociales, UNL. Cándido Pujato 2751, Santa Fe, CP: 3000, Argentina. Correo electrónico: vberros@fcjs.unl.edu.ar 
problemática de riesgos controvertidos o inciertos. La identificación de este conjunto de resoluciones permite pensar en la emergente construcción de una mirada precautoria que genera un conjunto de tensiones al interior del derecho de daños.

Palabras Clave

Riesgos ambientales - Daños ambientales. the issue of disputed or uncertain risks. Identifying this set of resolutions allows thinking in the arising construction of a precautionary vision that generates a set of tensions within the law regarding damages.

KEYWORDS

Environmental risks - Environmental damage.

\section{INTRODUCCIÓN}

El objetivo del presente trabajo consiste en mostrar uno de los resultados de una línea de investigación que, partiendo del vínculo entre derecho y riesgos, se ocupó de abordar decisiones judiciales sobre riesgos ambientales y relativos a la salud de carácter controvertido, con el fin de identificar las principales líneas argumentales construidas al interior de la jurisprudencia reciente así como las contradicciones epistemológicas, desafíos y agendas abiertas que se plantean en el campo del derecho de daños en Argentina ${ }^{1}$.

El criterio de selección de las sentencias analizadas se configura mediante dos parámetros.

Uno temático, dado que versan sobre el problema de la exposición a agroquímicos $^{2}$ y a radiaciones no ionizantes (emitidas por la instalación

${ }^{1}$ La investigación de referencia se enmarca en los resultados de la tesis doctoral de mi autoría titulada "Entramado precautorio. Un aporte desde el derecho para la gestión de riesgos ambientales y relativos a la salud humana en Argentina" dirigida por Gonzalo Sozzo (FCJS - UNL) y codirigida por Marie-Angèle Hermitte (Université de Paris I y EHESS, Paris, Francia) defendida públicamente el día 1 de marzo de 2013.

2 "Monsalvo, Cristina y otros c/ Delaunay, Jorge", s/ amparo, Corte Suprema de Justicia de la Provincia de Buenos Aires, 8 de agosto de 2012; "Arata, Antonio y otros c/Torino, Pío Alberto", s/acción de amparo, Juzgado Correccional de Garantías y de Menores 2a Nominación de San José de Metán, 29 de septiembre de 2011; "Picorelli, Jorge Omar y otra c/ Municipalidad de General Pueyrredón”, s/ amparo, Tribunal de Familia $N^{\circ} 2$ de Mar del Plata, 31 de junio de 2011; "Arrocera San Carlos SRL y Arrocera Cancha Larga S.A E/A Ferrau, Marco Antonio y otros c/ Municipalidad de Las Palmas y otros", s/ medida cautelar, Sala I de la Cámara Civil y Comercial de Apelaciones de la ciudad de Resistencia, 21 de febrero de 2011; "Cavigliano Peralta, Viviana y otros c/ Municipalidad de San Jorge y otros”, s/ amparo, Juzgado de Primera Instancia de Distrito en lo Civil, Comercial y Laboral de San Jorge del 16 de marzo de 2009, Sala II de la Cámara en lo Civil y Comercial de la ciudad de Santa Fe del 9 de diciembre de 2009, Juzgado de Primera Instancia de Distrito en lo Civil, Comercial y Laboral de San 
de antenas de telefonía móvil ${ }^{3}$ y por estaciones transformadoras de energía eléctrica $\left.{ }^{4}\right)$, ambas hipótesis de riesgos controvertidos cuya judicialización ha proliferado en los últimos años en el mencionado país.

Otro, vinculado con las articulaciones que se efectúan de diversa manera con el principio precautorio, positivizado en Argentina en el campo del derecho ambiental, y que permite colocar en un espacio central a los riesgos controvertidos.

Este principio, diseñado para el campo de las decisiones sobre riesgos, en Argentina ha sido muy utilizado en el ámbito jurisdiccional y los casos que forman parte de nuestro acervo documental dan cuenta de ello5. El mismo

Jorge del 21 de febrero de 2011 y nuevamente de la segunda instancia interviniente el 19 de abril de 2012 con aclaratoria del 16 de junio de 2012; "Di Vicensi, Oscar Alberto c/ Delaunay, Jorge” s/ amparo, Tribunal Criminal Nro 2 de Mercedes, 2 de abril de 2008. La Ley. "Suplemento" “Derecho Ambiental”, 15 (16 de diciembre de 2008) 2.

3 “Telecom Personal c/ Municipalidad de Carlos Paz”, s/ acción declarativa, Sala B de la Cámara Federal de Apelaciones de la $4^{a}$ Circunscripción Judicial, 3 de marzo de 2011; “R.J.C. c/ Municipalidad de Quilmes y otros”, s/amparo, Sala III de la Cámara Federal de La Plata, 18 de febrero de 2010; "CTI Compañía de Teléfonos del Interior S.A. c/ Municipalidad de Villa Ascasubi”, s/amparo, Juzgado Federal de Rio Cuarto, 19 de mayo de 2008; "Giménez, Juan Ramón c/ Empresa Telecom Personal S.A. y/o Municipalidad de la Eduvigis y/o Muñoz, Eulalio Enrique y/o quien resulte responsable", s/ amparo, Juzgado Civil y Comercial N 6 de Resistencia, 7 de febrero de 2008; "Agüero, Norberto y otros c/ Municipalidad de Cañuelas", s/ amparo, Sala III Cámara Federal de Apelaciones de La Plata, 25 der octubre de 2007; "Telefónica Comunicaciones Personales SA c/ Municipalidad de Lanús”, s/ acción declarativa de inconstitucionalidad, Sala I de la Cámara Federal de Apelaciones de La Plata, 28 de junio de 2007; "Calderón, Jorge c/ Municipalidad de Yala", s/amparo, Superior Tribunal de Justicia de la Provincia de Jujuy, 16 de abril de 2007; "Espíndola María c/ Movicom Bellsouth", s/ Daños Perjuicios, Juzgado de Primera Instancia en lo Civil $N^{\circ} 105$ de Buenos Aires, 9 de febrero de 2007.

4 “H.M.A. c/EDESUR y otros", s/ amparo, Sala II de la Cámara Federal de Apelaciones de La Plata, 9 de noviembre de 2009; "Defensoría del Pueblo de la Ciudad de Buenos Aires c/ GCBA y otros”, s/amparo, Cámara de Apelaciones en lo Contencioso, Administrativo y Tributario de la Ciudad Autónoma de Buenos Aires, 27 de marzo de 2008; "Edesur S.A. c/ Municipalidad de Berazategui”, s/sumarísimo, Sala I de La Cámara Federal de La Plata, 30 de agosto de 2007; "Alarcón, Francisco y otros c/ Central Dock Sud otros”, s/ daños y perjuicios, Cese de contaminación y perturbación ambiental de la Sala II de la Cámara Federal de Apelación de La Plata, 22 de mayo de 2006; "Asociación Coordinadora de Usuarios, Consumidores y Contribuyentes c/ ENRE-EDESUR" s/ cese de obra de cableado y traslado de Subestación Transformadora, Sala II de la Cámara Federal de Apelaciones de La Plata, 8 de julio de 2003.

${ }^{5}$ Por supuesto, no se trata de los únicos problemas que han sido tematizados a partir de este principio. En tal sentido, ya se han efectuado varios trabajos de recopilación y análisis de casos heterogéneos. Puede consultarse: Bestani DE SEguir, Adriana El principio de precaución en la jurisprudencia de la Suprema Corte de Justicia de la Nación 
se encuentra incorporado en la Ley $\mathrm{N}^{\circ} 25.675$ que prevé la política ambiental nacional y lo define como uno de sus principios del siguiente modo: "Cuando haya peligro de daño grave o irreversible la ausencia de información o certeza cientifica no deberá utilizarse como razón para postergar la adopción de medidas eficaces, en función de los costos, para impedir la degradación del medio ambiente".

Nuestro punto de partida consiste en la expansión, en los últimos años, de un conjunto de decisorios en la jurisprudencia argentina que resuelven sobre hipótesis de riesgos controvertidos en relación al ambiente y a la salud humana, es decir, hipótesis cuyas consecuencias se discuten con un mayor o menor grado de intensidad en el ámbito científico y que se encuentran complejizadas, en multiplicidad de ocasiones, por insumos provenientes de otros ámbitos de producción de conocimientos. Este proceso ha canalizado una confluencia entre el derecho de daños -que tradicionalmente se ha ocupado del problema de daños y riesgos en Argentina- y el derecho ambiental que incorpora la problemática de lo incierto y controversial.

Ello que se visualiza en la jurisprudencia reciente que da cuenta de la judicialización de conflictos socio-ambientales a través de diferentes estrategias. Por un lado, mediante acciones por daños y perjuicios. Por otro, se identifica la recurrencia a vías de tutela inhibitoria que, como materialización de la función preventiva del derecho de daños, constituyen los mecanismos de acceso a la jurisdicción que el operador jurídico encuentra disponibles en el derecho vigente ${ }^{6}$.

Ambas estrategias presentan un problema medular en relación al conflicto que traducen. Tanto las acciones por daños como los mecanismos de tutela inhibitoria dan cuenta de las funciones de reparación y de prevención del derecho de daños y trabajan con supuestos de riesgos conocidos o cognoscibles. Es decir, sobre daños ya materializados o que, no habiéndose producido, de manera inminente pueden desenvolverse, es decir, sobre riesgos previsibles.

Los conflictos socio-ambientales que abordamos en el presente estudio se

en Jurisprudencia Argentina. Doctrina. Dic. (2011); y Uso (¿y abuso?) jurisprudencial del principio de precaución en la tutela procesal ambiental: el rol del juez, reglas probatorias e incertidumbre cientifica en Revista de Derecho Ambiental, 17 (2010); DRNAS DE CLÉmENT, Zlata El principio de precaución ambiental. La práctica argentina (Córdoba, Lerner, 2007).

${ }^{6}$ La función preventiva del derecho de daños, muy elaborada por la doctrina argentina, contaba con escasos mecanismos específicos para ser canalizada, tal y como algunos autores han señalado. Véase: Sozzo, Gonzalo, La prevención del daño (ensayo desde la mirada de las vías periféricas) en Revista de Derecho Privado y Comunitario, 1 (2008). Cabe señalar que la reciente sanción del Código Civily Comercial unificado que comenzará a regir a partir de 2016 establece expresamente la función preventiva del derecho de daños así como prevé una acción preventiva específica (artículos 1710 ss.) 
alejan de tales características. Se trata de casos en los que se muestra cardinal la controversia y el desconocimiento, la variabilidad y diversidad de posiciones. No se visualizan ni daños ni riesgos ciertos como condición tanto para la reparación-recomposición como para la prevención respectivamente ni, tampoco, es fácilmente traducible a este tipo de temas la adecuada relación de causalidad que adopta la legislación civil vigente. Con esto se genera una tensión medular con el campo del derecho de daños que exige de estos requisitos como condición de funcionamiento.

Aún ante este escenario que parece redireccionar hacia otras maneras de afrontar los problemas inciertos y no causalmente probados según los cánones clásicos, debe decidirse. En este grupo de decisiones se advierten algunas reformas de las herramientas preventivas en un sentido precautorio. Asimismo, se identifican las agendas que quedan abiertas para mejorar las decisiones judiciales ante este tipo de hipótesis cuya tendencia es a expandirse en el momento contemporáneo. Momento que, un conjunto de miradas y contribuciones teóricas caracterizan como emergencia de la sociedad del riesgo ${ }^{7}$, o bien, de transición hacia un paradigma diferente del actual, aunque aún sin contornos claramente delineados ${ }^{8}$.

En los apartados siguientes se presenta una revisión sobre el modo en que desde la jurisprudencia comienza a construirse lo que denominamos una "emergente mirada precautoria". En primer término, se focaliza en el proceso de flexibilización respecto de los requisitos que contienen las vías de tutela inhibitoria, lo que se ha venido desarrollando a los fines de canalizar demandas que, por su carácter precautorio, no cuentan con vías propias de acceso a la jurisdicción. En segundo lugar, se efectúa una reconstrucción sobre el abordaje que sobre el problema de daños y riesgos se va delineando por parte de jueces y juezas para, finalmente, elucidar qué transformaciones aparecen en torno a la relación de causalidad en sus líneas argumentales.

\section{MeCANismos de ACCESO A LA JURISDiCCIÓN ANTE HIPÓTESIS PRECAUTORIAS}

Dentro del conjunto de casos que han decidido sobre los temas abordados, si bien existen resoluciones que descartan de plano los reclamos por no considerar adecuada la vía de tutela inhibitoria utilizada, en paralelo, aparece un grupo de sentencias en que se comienza a problematizar esta situación,

${ }^{7}$ BeCK, Ulrich, La sociedad del riesgo mundial (Barcelona, Paidos, 2007); BECK, Ulrich, La sociedad del riesgo global (Barcelona, Siglo XXI, 2002); BECK, Ulrich, La sociedad del riesgo. Hacia una nueva modernidad (Barcelona, Paidos, 1998)

${ }^{8}$ Santos, Boaventura de Sousa, Crítica de la razón indolente. Contra el desperdicio de la experiencia (Bilbao, Desclée de Brouwer, 2003) 
en particular, por la inexistencia de una vía de acceso a la jurisdicción creada especialmente para hipótesis precautorias. De hecho, en principio, estas construcciones no aparecen pensadas para el tratamiento de casos a los que subyacen riesgos de carácter incierto y, gran parte de ellas, guardan estrecha relación con la función preventiva del derecho que indica como meta el tomar medidas sobre riesgos probables antes de su acaecimiento?.

En este marco se destaca especialmente la acción de amparo que, en este conjunto de resoluciones, es considerado como vía adecuada para la canalización de los reclamos. Además de este instituto se suman otros que han viabilizado la judicialización de conflictividades relativas tanto a radiaciones no ionizantes como la utilización de agrotóxicos. Así se advierten intentos heterogéneos, verbigracia, mediante el impulso asignado a las inmisiones inmateriales entre vecinos. En estos institutos la certeza es medular para su puesta en marcha y esto es tematizado en parte de las sentencias que aquí se presentan, que podrían configurar una cierta metamorfosis de los mecanismos vigentes para atender situaciones inciertas, a la vez que ponen de relieve la inexistencia de una vía de tutela propia para canalizar hipótesis de precaución ${ }^{10}$.

\section{La acción de amparo ante lo controvertido o incierto.}

La acción de amparo es una de las vías de tutela inhibitoria más utilizadas para llevar a la instancia jurisdiccional este y otro tipo de casos.

El amparo, largamente gestado antes de su consagración a nivel legislativo, se encuentra regulado por un importante repertorio de normas en el ordenamiento legal argentino. En primer término, se lo consagra en la primigenia Ley $\mathrm{N}^{\circ} 16.986 / 66$, luego se da lugar a la incorporación al Código Procesal Civil y Comercial de la Nación del amparo contra particulares mediante la Ley $\mathrm{N}^{\circ} 17.454 / 68$, a posteriori se lo introduce a nivel constitucional en la reforma de 1994 en el artículo 43 CPol.Arg; a lo que se agregan las múltiples regulaciones existentes de índole provincial dada la conformación federal del Estado argentino. Asimismo, en materia ambiental, la Ley $\mathrm{N}^{\circ} 25.675 / 02$ prevé la figura del amparo ambiental colectivo en su artículo 30 que ha sido calificado como un sub-tipo dentro de los amparos.

${ }^{9}$ Se ha sostenido ya que la tutela inhibitoria definitiva postula la prevención del daño y "el supuesto de hecho es la existencia de un perjuicio que aparece como causalmente previsible": LORENZETTI, Ricardo, Las normas fundamentales de derecho privado (Santa Fe, Rubinzal Culzoni, 1995), p. 289.

${ }^{10}$ Sozzo, Gonzalo - Berros, María Valeria, Principio precautorio en Revista de Responsabilidad Civil y Seguros. La Ley, III, 28, (2011); Sozzo, Gonzalo - Berros, María Valeria, Una agenda para el principio precautorio en Revista Critica de Derecho Privado. La Ley Uruguay, 6 (2009) 
En los casos que llevan a la instancia judicial este tipo de problemas, existe un conjunto que no llega a etapa de resolución dado que se lo rechaza por la no idoneidad como vía de acceso a la jurisdicción. Los fundamentos son, en general, la no acreditación de la inminencia del daño lo que se articula con el carácter controversial que asumen estas temáticas en el campo científico, conjugado esto último con otros canales de producción de saberes que lo interrogan y colocan en crisis.

Ahora bien, en concomitancia, se han construido líneas argumentales en las que las referencias a la admisibilidad del amparo difieren. Tal es así que se lo considera como vía adecuada para plantear estas conflictividades. En particular, se alude a la amplitud y razonabilidad que debería aplicarse en cuanto a la declaración de admisibilidad del amparo, consolidándose así una tendencia a la reforma de este instituto de cara a hipótesis precautorias.

Se advierten afirmaciones en tal sentido en la causa "Defensoría del Pueblo de la Ciudad de Buenos Aires c/ Gobierno de la Ciudad de Buenos Aires y otros s/ amparo" resuelta por la Sala I de la Cámara en lo Contencioso, Administrativo y Tributario de la Ciudad Autónoma de Buenos Aires en fecha 27 de marzo de 2008. Se trata de un conflicto generado por la existencia de un transformador de energía eléctrica en el terreno de una escuela primaria frente a lo cual interviene la Defensoría del Pueblo. Solicita que el mismo sea retirado de inmediato por los riesgos para la salud de quienes allí asisten ocasionados por: $i$ ) la existencia de PCBs en la cámara transformadora, lo que luego es descartado por las pericias efectuadas; y ii) la exposición continua a radiaciones no ionizantes.

La acción es rechazada en la primera instancia. La Cámara, por el contrario, hace lugar al amparo y determina que su admisibilidad debe responder a criterios razonablemente amplios lo que en el caso se articula directamente con la presencia de dicho artefacto en el predio escolar. Se esgrime en particular que "no por ello puede calificarse al amparo como una acción excepcional. Por el contrario, toda vez que ésta constituye una garantía constitucional, para tutelar de modo rápido y eficaz los derechos y garantías establecidas para protegerlos, la procedencia de aquél debe ser analizada con criterio razonablemente amplio, resultando admisible siempre que el proceder impugnado reúna las caracteristicas y efectos que prevén los textos constitucionales. Por ello, el amparo resultará idóneo siempre que, conforme a la prudente ponderación de las circunstancias del caso, la acción u omisión cuestionada reúna prima facie los caracteres de ilegitimidad y/o arbitrariedad manifiesta y, asimismo, ocasione - en forma actual o inminente - una lesión, restricción, alteración o amenaza de derechos o garantias constitucionales"11.

${ }^{11}$ Sentencia "Defensoría”. 
Esta acción también es considerada admisible en otros supuestos relativos a radiaciones aunque provenientes de antenas de telefonía celular. Así, en la causa "Giménez, Juan c/ Empresa Telecom Personal S.A y/o Municipalidad de la Eduvigis y/o Muñoz, Eulalio Enrique y/quien resulte responsable s/ amparo" resuelta por el Juzgado en lo Civil y Comercial Nro 6 de Resistencia el 7 de febrero de 2008, incluso, se ha sostenido una defensa 'política' de esta herramienta para la tutela de derechos afirmándose que "el argumento de la sobredimensión de amparos much as veces vela una resistencia que opone la autoridad frente a los avances que pretenden controlarla o encausarla. El amparo constituye una garantía legitima de la ciudadanía frente a los avances ilegales o arbitrarios del poder, que no sólo reside en las autoridades públicas sino también en los grupos o intereses que muchas veces son más poderosos" 12 . Se trataba aquí de un reclamo de parte de un vecino por la instalación de una antena de telefonía en el inmueble lindante al propio solicitándose se prohíba con la continuación de esta tarea y se remueva lo efectuado hasta el momento lo que es acogido por el juez interviniente.

En la causa "Calderón, Jorge c/Municipalidad de Yala s/amparo" resuelta por el Superior Tribunal de Justicia de la Provincia de Jujuy el 16 de abril de 2007 también se expresa que "el riesgo en los daños a la salud de las personas -y el derecho a un medio ambiente sano, equilibrado, apto para el desarrollo bumano sin comprometer el de las generaciones futuras-constituia la 'amenaza' requerida por el art. 43 para la procedencia de la vía"13.

En relación al problema de agroquímicos también existen amparos que han sido admitidos. En la causa "Picoreli, Jorge y otro/a c/Municipalidad de General Pueyrredón s/amparo" resuelta por el Tribunal de Familia N² de Mar del Plata en fecha 31 de mayo de 2011 se hace lugar a esta acción conducente a que se efectivice por parte de la Municipalidad demandada la puesta en marcha y reglamentación de la Ordenanza Municipal N 18740/2008 que impone una serie de importantes prohibiciones en cuanto al uso y manejo de plaguicidas ${ }^{14}$. Se sostiene que "Es pacifica la jurisprudencia en referencia a que la tutela judicial brindada por la acción de amparo no funciona como vía

\footnotetext{
${ }^{12}$ Sentencia "Giménez".
}

${ }^{13}$ Sentencia "Calderón".

${ }^{14} \mathrm{Su}$ artículo 1 prevé la "Probibición de utilización de cualquier plaguicida de sintesis u otro producto de similar utilización de aplicación agropecuaria o forestal; el tránsito de maquinaria terrestre cargada con cualquier plaguicida de sintesis o producto similar y el descarte o abandono en el ambiente terrestre, acuático y/o urbano de envases de cualquier plaguicida de sintesis o producto similar, dentro de un radio de 1000 metros a partir de las plantas urbanas o núcleos poblacionales". Cabe señalar que se hizo lugar al amparo y se ordenó al Departamento Ejecutivo de la Municipalidad del Partido de General Pueyrredón que en veinte días reglamente la ordenanza. 
subsidiaria, sino que reviste carácter de alternativa principal cuando los derechos lesionados constituyen enunciados básicos constitucionalmente reconocidos, en el caso el derecho a la salud y el mantenimiento de una adecuada calidad de vida y afectación del derecho ambiental. En definitiva, las normas que instrumentan el acceso a la jurisdicción hasta las que dan validez constitucional a las sentencias deben interpretarse en el sentido que conduzcan necesariamente a un adecuado servicio de justicia sin que sean obstáculo gratuitos ritualismos que frustran el fin último del proceso, ocasionando a la postreperjuicios de dificil reparación ulterior" 15 .

Por último, se destaca la causa "Peralta, Viviana c/Municipalidad de San Jorge y otros s/amparo" resuelta por el Juzgado de Primera Instancia de Distrito $\mathrm{N}^{\circ} 11$ en lo Civil, Comercial y Laboral de la ciudad de San Jorge en fecha 10 de junio de 2009 y por la Sala II de la Cámara de Apelaciones en lo Civil y Comercial de la ciudad de Santa Fe el 9 de diciembre de 2009 y reconfirmada por el a quo el 21 de febrero de 2001 y nuevamente reconfirmada por la Cámara el 19 de abril de $2012^{16}$. El reclamo se interpone por un grupo de vecinos que demandan se prohíban las fumigaciones terrestres a 800 metros y las aéreas a 1.500 metros de la zona urbana de la localidad de San Jorge, en la Provincia de Santa Fe, una de las más importantes regiones agrarias, contra los propietarios de los inmuebles y quienes llevan a cabo actividades de fumigación en ellos, la Municipalidad de San Jorge por omisión de delimitación de la línea agronómica tal como establece la Ley Provincial $\mathrm{N}^{\circ} 11.273 / 1995$ y la Provincia de Santa Fe por omisión de control.

En la primera resolución de esta serie se establece un apartado dedicado expresamente al vínculo entre acción de amparo e hipótesis que se enrolan en el principio precautorio. En ésta se afirma que "luego de haber analizado ambos Institutos y haber señalado sus rasgos caracteristicos, centraré ahora mi análisis en la relación de ambos, a fin de determinar si existe algún óbice lógico que impida la invocación del 'principio precautorio' en una acción de amparo. Para ello, tomaréalgunos requisitos esenciales para la procedencia de la acción de amparo, y los analizaré desde la concepción del 'principio protectorio ${ }^{17}$, a fin de

${ }^{15}$ Sentencia "Picorelli".

${ }^{16}$ Comentario a las sentencias citadas - a excepción de la emitida a posteriori en fecha 19 de abril de 2012- en LoRenzetTi, Pablo Agroquimicos versus principio precautorio ¿una opción trágica? en Revista de Derecho Ambiental, 27 (2011). Asimismo, en el apartado 7 del artículo de: ANDrada, Alejandro - Hernández, Carlos Soja, principio precautorio y agroquímicos en Revista de Derecho de Daños, 1 (2011); y en el capítulo $5^{\circ}$ del libro de: Marchiaro, Enrique, Soja y derecho municipal ambiental. Potestades $y$ límites jurídicos de los municipios argentinos frente al monocultivo y los agroquimicos (Buenos Aires, Ediar, 2011).

${ }^{17}$ Aquí parece darse un "lapsus" y estar realmente refiriendo al principio precautorio. 
determinar su procedencia o improcedencia [...] creo resulta a todas luces viable la invocación del 'principio precautorio' como fundamento para la adopción de medidas en una acción de amparo. En efecto, tal como hemos visto, la supuesta contradicción entre ambos Institutos, no es tal ya que el peligro inminente y la arbitrariedad manifiesta requerida por el amparo, se presenta en la amenaza que deriva de la falta de certeza cientifica, en ambos sentidos, respecto de una actividad; $y$ tal amenaza es inminente y manifiesta"18.

En la segunda instancia se anuda el tema con la especificidad que asume este instrumento en los casos ambientales y, en particular, se alude a la cuestión de la sustanciación de la prueba. Entre los demandados se presentó como inadecuada esta vía de tutela, entre otras razones, debido a que no admitiría un "ámbito de debate amplio y de demostraciones cientificas necesarias, no constituyendo la vía de amparo -por la estrechez de sus términos-el trámite adecuado"19. Frente a este argumento se afirma "me permito señalar enfáticamente que la cuestión no requiere de mayor amplitud en cuanto a 'debate' y 'prueba'. Pues bien por medio del presente se discute sobre actos que atentan contra el medioambiente, repercutiendo de manera directa en la salud de los vecinos de la ciudad de San Jorge, lo que importa que existe un factor de urgencia que no puede ser atendido si no es por medio del amparo, asi lo plantearon los actores y asi lo entendió el juez a quo, al franquear esa vía con respaldo constitucional"20.

Los parágrafos hasta aquí transcriptos permiten visualizar la existencia de una suerte de apertura en cuanto a la potencialidad del amparo para trabajar con hipótesis de riesgos inciertos. Se modalizan sus requisitos de operatividad no sólo por la trascendencia de esta suerte de 'control difuso' canalizada a través de las herramientas de tutela inhibitoria sino, también, y de manera cardinal por el tipo de derechos cercenados protegidos constitucionalmente.

La falta de certeza científica sobre los perjuicios que podrían generar los "agentes contaminantes" complica el análisis de sus requisitos de procedencia en cuanto remiten a la existencia de una lesión, alteración o amenaza actual o inminente, lo que no suele ser claramente estimable ante hipótesis de precaución. Sobre este punto se advierten algunas referencias en dos sentidos.

${ }^{18}$ Sentencia "Peralta" de 10 de junio de 2009. En el dictamen del fiscal interviniente, Carlos Stegmayer, se esgrime también la procedencia de esta vía de tutela inhibitoria considerándose que se cumple con todos sus presupuestos: $i$ ) se trata del medio judicial más idóneo; ii) está dirigido contra actos y omisiones de autoridades públicas o de particulares, iii) estos actos y omisiones en forma actual o inminente restringen, alteran o amenazan con arbitrariedad manifiesta $i v$ ) derechos y garantías consagrados a nivel constitucional. Dictamen Fiscal 5 de junio de 2009.

${ }^{19}$ Sentencia "Peralta", Segunda instancia.

${ }^{20}$ Sentencia "Peralta", Segunda instancia. 
El primero remite a que el hecho mismo de la existencia de la incerteza configura la amenaza, a lo que sigue su calificación como inminente y manifiesta. El segundo esgrime que esta situación no requiere de una mayor amplitud en el debate -lo que implicaría canalizar otra vía diferente del amparo que posee una fuerte estrechez probatoria- debido a que la afectación de bienes relevantes como el ambiente y la salud conducen a un escenario urgente que, por tanto, puede ser trabajado mediante esta vía de tutela cuya raigambre consiste justamente en atender situaciones que no pueden esperar.

\section{Otra estrategia utilizada: las inmisiones inmateriales entre vecinos.}

En una de las resoluciones que integran el corpus de sentencias estudiadas, "Espíndola María c/ Movicom Bellsouth s/ daños perjuicios" resuelta por el Juzgado Civil de Primera Instancia $\mathrm{N}^{\circ} 105$ de la localidad de José C. Paz el 9 de febrero de 2007 se trabaja a partir del art. 2618 del Código Civil que constituye el argumento central de la actora.

Este artículo regula las inmisiones inmateriales entre vecinos en el Código Civil actualmente vigente en Argentina, dentro de los límites y restricciones al dominio ${ }^{21}$. Esta norma, cuya fuente se ha señalado en el Código italiano de 1942, establece que: "Las molestias que ocasionen el humo, calor, olores, luminosidad, ruidos, vibraciones o daños similares por el ejercicio de actividades en inmuebles vecinos, no deben exceder la normal tolerancia teniendo en cuenta las condiciones del lugar y aunque mediare autorización administrativa para funcionar. Según las circunstancias del caso, los jueces pueden disponer la indemnización de los daños o la cesación de tales molestias. En la aplicación de esta disposición el juez debe contemporizar las exigencias de la producción y el respeto debido al uso regular de la propiedad; asimismo tendrá en cuenta la prioridad en el uso. El juicio se tramitará sumariamente".

En este caso se plantea que hace cinco años la demandada instaló una torre de telefonía móvil en el inmueble lindero que ocasiona molestias, ruidos intensos y permanentes, luces intensas y gases así como, también, interferencias con aparatos eléctricos de uso cotidiano, lo que se agrava considerando que la actora es una persona no vidente. Se enumera de este modo una diversidad

${ }^{21}$ La redacción del artículo 1973 del Código que comenzará a regir en 2016 es muy similar a la actual: "Inmisiones. Las molestias que ocasionan el humo, calor, olores, luminosidad, ruidos, vibraciones o inmisiones similares por el ejercicio de actividades en inmuebles vecinos, no deben exceder la normal tolerancia teniendo en cuenta las condiciones del lugar y aunque medie autorización administrativa para aquéllas. Según las circunstancias del caso, los jueces pueden disponer la remoción de la causa de la molestia o su cesación y la indemnización de los daños. Para disponer el cese de la inmisión, el juez debe ponderar especialmente el respeto debido al uso regular de la propiedad, la prioridad en el uso, el interés general y las exigencias de la producción". 
de inmisiones aunque el foco se coloca sólidamente sobre los ruidos, luces y gases que despide el artefacto.

La actora pretende una indemnización por los daños sufridos tanto patrimoniales como extra-patrimoniales y la cesación del funcionamiento de la estructura. Se demanda, por una parte, a la empresa de telefonía que opone excepción de prescripción. Por la otra, a la Municipalidad de José C. Paz por falta de control, que esgrime la inexistencia de habilitación respecto de la instalación realizada.

Si bien no planteado inicialmente, el cuadro de argumentos que iluminan la cuestión de las posibles consecuencias dañosas en la salud devenidas de la emisión de radiaciones no ionizantes es recuperado a lo largo del proceso por el juez en aplicación explícita de la regla "iura novit curia". Afirma en ese sentido la sentencia que: "aún cuando la actora no bubo planteado en autos, el daño potencial que surge de la exposición permanente a la radiación electromagnética, las que aún por debajo de los límites permitidos en la legislación vigente, resultan potencialmente peligrosos. Conclusiones a las que han arribado, en múltiples Tribunales la de Unión Europea ${ }^{22}$, que han establecido el daño potencial en la salud por la exposición permanente a radiaciones no ionizantes de instalaciones de telefonia móvil. Como asi también, la Organización Mundial de la Salud (OMS), prevé establecer para el año 2007 un Protocolo que establezca el limite de radiaciones no ionizantes de telefonia móvil y de todo tipo de campos electromagnéticos, por debajo de las permitidas actualmente por las normativas vigentes a nivel mundial. Esto es por considerarlas, a dichas radiaciones nocivas para la salud, con efectos que se prolongan en el tiempo y que se manifiestan en daños genéticos, según datos estadísticos manejados por la OMS"23.

En esta resolución la potencialidad de daños conduce al resarcimiento

${ }^{22}$ Cita una sentencia del Juzgado de Primera Instancia $\mathrm{N}^{\circ} 2$ de Bilbao del 09.06.2001 y otra de la Sala en lo Contencioso Administrativo del Tribunal Superior de Justicia de Castilla y León con sede en Valladolid del 16.05.2001, ambos de España. En el primer caso se anula un acuerdo entre una comunidad de propietarios y una empresa de telefonía por oponerse uno de los vecinos y se afirma que "las radiaciones no ionizantes de baja potencia y alta frecuencia, de la telefonia móvil en particular, resultan razonablemente sospechosas de no ser anodinos con relación a la salud de los seres humanos que se expongan permanentemente a los mismos, hallándose el campo menos dudoso de probabilidad patológica en la afectación del sistema nervioso, y el riesgo más evidente, de confirmarse la sospecha, para los niños". En el segundo supuesto se clausura la actividad de estaciones de base construidas en el techo de un establecimiento educativo señalándose que es susceptible de producir riesgo para las personas. Véase: EMBID TELLO, Antonio Eduardo, El principio de precaución, en SAnTAmaría PAStor, J. A. y otros, Los principios jurídicos del derecho administrativo (Madrid, La Ley, 2010).

${ }^{23}$ Sentencia "Espíndola". 
de parte del tribunal en términos de daño potencial a la salud fijando un monto debido por tal rubro ${ }^{24}$.

Podría apuntarse este fallo como una materialización de la idea de función precautoria del derecho de daños, lo que conduce a interrogar la posibilidad de repensar el programa del derecho de daños asumiendo este tipo de funcionalidad -lo que tampoco requeriría necesariamente un planteo en términos indemnizatorios- o elucidar si se presenta como más adecuada la generación de mecanismos de tutela informados por una teoría jurídica pensada en articulación con "lo incierto". Este es un debate planteado en Argentina en el que, por una parte, se postula la necesidad de pensar en una nueva función para el derecho de daños: la función precautoria ${ }^{25}$. Y, por la otra, se descarta esta posibilidad lo que ha sido traducido en el Código Civil y Comercial unificado que incorpora la función preventiva explícitamente y no así la precautoria.

\section{III. ¿CÓMO CONCEBIR EL PROBLEMA DE RIESGOS CONTROVERTIDOS?}

Las hipótesis que pueden ser analizadas a partir del principio precautorio no son homogéneas. Por el contrario, en términos analíticos podrían identificarse escenarios calificados como 'inciertos' dado que las informaciones que circulan carecen de entidad como para delinear los diversos posicionamientos de modo claro. Verbigracia, actualmente existe un menor grado de conocimiento de la exposición a antenas de telefonía celular por comparación a las consecuencias vinculadas al uso de aparatos móviles. En este último caso, se torna más palpable la reconstrucción de la controversia científica a la luz de una emergente cantidad de trabajos recientes al respecto. También se pueden

24 "b) Daños potenciales a la salud: Por lo que fijo prudencialmente el monto de la indemnización correspondiente al daño a la salud, la suma de pesos cinco mil (\$5000), con más sus intereses que se computan desde la fecha de instalación de la antena autosoportada (febrero de 1998) hasta su efectivo pago, sobre la tasa de interés pasiva que suministra el Banco Central de la República Argentina". Sentencia "Espíndola"

${ }^{25}$ En ese sentido se destaca uno de los primeros artículos que se pronuncia sobre el tema ante la incorporación, del principio de precaución al ordenamiento jurídico argentino: CAFFERATta, Néstor - Goldemberg, Isidoro, El principio de precaución JA 6-IV (2002). Asimismo, en 2011 las conclusiones del las XXIII Jornadas Nacionales de Derecho Civil desarrolladas el 29 y 30 de septiembre y el 1 de octubre de 2011 en su Comisión $\mathrm{N}^{\circ} 3$, Derecho de daños, luego de la presentación de veintidós ponencias versadas sobre el tema de la prevención y la precaución, concluyó por mayoría que " $E l$ principio precautorio es un principio general del derecho de daños que impone el deber de adoptar medidas adecuadas con el fin de evitar riesgos de daños potenciales a la vida, la salud y el ambiente". 
identificar este tipo de controversias, por ejemplo, en el caso de la exposición a agroquímicos o de plantas transformadoras de energía eléctrica. En ambos supuestos se movilizan una pluralidad de estudios importantes sobre las consecuencias que generarían sobre la salud y el ambiente, que conviven con una pléyade de ejercicios de epidemiología popular ${ }^{26}$.

Lo expuesto indica la necesidad de efectuar un esfuerzo hacia la reconstrucción del "parlamento científico" ${ }^{27}$, es decir, de las diversas posturas que se movilizan sobre un mismo tema, y, en paralelo, la canalización de otros saberes que han recabado información y consolidado datos relevantes sobre las hipótesis en torno a las que debe decidirse.

Las ideas de incerteza y de controversia aunadas al concepto de riesgos, aparecen en las resoluciones judiciales. En éstas, de similar forma, se conduce a diferentes medidas sustentadas con mayor o menor grado en el principio precautorio. Se califica la hipótesis de riesgo de manera tal que conduce a adoptar o no decisiones inmersas en heterogéneos procesos de resistencia a riesgos.

En tal contexto, existen resoluciones que consideran que la controversia posee suficiente entidad como para traducirse en términos de certeza y otras que, aún dentro de lo no acabadamente conocido, conducen a la adopción de decisiones precautorias, lo que se combina con aplicaciones sustanciales o procedimentales del principio. Las aplicaciones sustanciales consisten en la toma de decisiones de fondo sobre la temática llevada a la instancia judicial lo que acontece en la mayor parte de los supuestos. La aplicación de índole procedimental refiere a una indicación procedural a seguir para que la autoridad que se determine adopte la decisión ${ }^{28}$, lo que se verifica, por ejemplo, en la causa "Peralta".

${ }^{26}$ Los ejercicios de epidemiología popular son aquellos realizados, en la mayor parte de los casos, por los propios afectados. Ya se ha reflexionado sobre las labores de las víctimas y la construcción de una nueva subjetividad. En términos generales, se lo plantea cómo la posibilidad de que este colectivo pueda configurar un nuevo sujeto político. Véase: Hermitte, Marie-Angèle La fondation juridique d'une société des sciences et des techniques par les crises et les risques en Burton-Jeangros C. y otros, Face au risque (Georg Saint-Rémy-de-Provence, L'Equinoxe, 2007). Asimismo, se ha aludido a diferentes roles que asumen las víctimas entre los que se destaca el de producir conocimiento Sozzo, Gonzalo Las víctimas del daño ambiental (la construcción de una nueva subjetividad) en Revista de Derecho de Daños, 1 (2011).

${ }^{27}$ Esta idea de un "Parlamento científico" permite graficar el modo en que actualmente se producen conocimientos: Latour, Bruno, Politiques de la nature. Comment faire entrer les sciences en démocratie (Paris, La Decouverte, 2004).

${ }^{28}$ Ewald, François, L'État de précaution en Rapport public du Conseil d'Etat.Jurisprudence et avis de 2004, en Responsabilité et socialisation du risque. La Documentation Française. Études et documents, 56 (2004) 
En el primer caso se destaca la resolución "Defensoría del Pueblo" en la que la controversia se traduce en términos de certeza. Se afirma que: "No existe incertidumbre en cuanto a que, de acuerdo al estadio actual de avance cientifico en relación a este tema, la exposición a campos electromagnéticos supone, sin lugar a dudas, un riesgo cierto y concreto para la salud de las personas que concurren diariamente al establecimiento educativo. A su vez, esta situación se ve agravada, en el caso de autos, por la circunstancia de que dicho peligro se proyecta sobre la salud de niños y niñas en edad escolar que, como es sabido, por razones biológicas resultan mucho más vulnerables a este tipo de daños que los adultos. Ello asi en tanto al encontrarse en una etapa de crecimiento, presentan una tasa de multiplicación celular muy elevada pero, al mismo tiempo, no poseen aún un sistema inmunológico completamente desarrollado". Tal apreciación condujo a ordenar se retire la cámara transformadora de energía eléctrica por las consecuencias que acarrea en la salud de las personas expuestas lo que es tenido como probado.

En el segundo conjunto se identifica un grupo de sentencias más amplio que focaliza en la cuestión controversial y canaliza decisiones precautorias en dos niveles. Por un lado, ordenando prohibiciones o desmantelamientos de antenas de telefonía fundados en una calificación de la controversia no ya en términos de riesgo "cierto y concreto" sino dentro del plano de aquello no suficientemente conocido pero no por ello desatendible. Por otro, indicando medidas para conocer mejor las hipótesis llevadas a la instancia judicial, lo que opera en algunos supuestos como una aplicación procedimental del principio precautorio como afirmamos ut supra, o bien, ordenando la adopción de medidas de gobierno de riesgos a las autoridades competentes.

Dentro del primer sub-conjunto en que se ordenan prohibiciones o desmantelamientos, se destaca la sentencia "Giménez" en la que se esgrime que "Los informes, artículos y opiniones de expertos se pronuncian en sentido divergente, considerando algunos que las referidas antenas celulares son nocivas para la salud y el ambiente; otros, determinándose por su inocuidad;y concluyendo los más que el tema merece mayores estudios que se están realizando, en especial por parte de la Organización Mundial de la Salud"29. A ello se agrega una consideración especial sobre una de las facetas de la controversia que refiere a la causación o favorecimiento de la aparición de cáncer: "Este efecto es uno de los de mayor controversia. Hay numerosos estudios (como el del Dr. Carlo) que establecen una vinculación entre el uso de TM y algunos tipos de cáncer (especialmente de zonas superficiales del cerebro, cáncer ocular, linfoma, etc.), mientras otros estudios dicen que las pruebas no son suficientes o consistentes para mostrar una correlación...Pese a los numerosos estudios

\footnotetext{
${ }^{29}$ Sentencia "Giménez".
} 
realizados, aún continúan las controversias respecto a la existencia $o$ no de los efectos cancerigenos. Existen muchas contradicciones en los resultados obtenidos, pero no se han encontrado grandes incrementos del riesgo de ningún tipo de cáncer, ni en niños ni en adultos" ${ }^{30}$.

También sobre el problema de la ubicación de antenas, se advierte la sentencia del Juzgado Federal $N^{\circ} 1$ de Neuquén de fecha 9 de abril de 2007, “Koenig, Daniel c/Municipalidad de Neuquén s/acción de amparo". Aquí se demanda a la empresa Telefónica Movistar S. A. y al Municipio de Neuquén para que se ordene la desconexión, el desmantelamiento y el traslado de una antena ubicada en la zona céntrica de la ciudad. El juez a quo efectúa indicaciones relevantes sobre la controversia que subyace a esta problemática, "Si bien la presentante admite que la evidencia cientifica sobre los perjuicios que ocasionan las radiaciones no ionizantes de las antenas de estaciones de telefonia celular no es concluyente ni aceptada unánimemente, afirma que existe una alta posibilidad de que las conclusiones de los estudios acompañados sea certera [...]. Se ha acreditado en cambio, en el escaso grado de certeza que el embrionario desarrollo del trámite exige, que no existe aún certeza cientifica sobre los efectos de la exposición a la radiación indiscriminada de microondas - que genera la red de telefonia móvil sobre la población-provocan en la salud. Los estudios en copia acompañados sostienen que ella produce efectos biológicos indeseables y ocasiona un riesgo para la salud pública"31.

La incerteza que se manifiesta se acompaña de una valoración que le asigna entidad suficiente como para adoptar medidas. Se sostiene que: "No cualquier magnitud de riesgo potencial justifica cualquier medida de precaución, en especial si esta última supone una carga importante para la sociedad, por ejemplo, por implicar la pérdida de un gran número de puestos de trabajo. Otra exigencia del principio de precaución es la transparencia en la difusión de los riesgos potenciales de ciertos productos o actividades, así como en la toma de decisiones por parte de autoridades. No es justo que en una sociedad democrática las industrias oculten riesgos potenciales de los productos que lanzan al mercado... Pero la gravedad de los riesgos potenciales que para la salud de la población de la ciudad de Neuquén en general importa la permanencia de la antena en la zona céntrica en la cual está instalada exigen actuar con premura, aplicando los principios vigentes en el orden internacional y nacional que tienden todos a la efectiva y urgente tutela tendiente no sólo a prevenir el daño proveniente de un riesgo conocido, sino también de aquellos riesgos inciertos pero potenciales" 32 .

\footnotetext{
${ }^{30}$ Sentencia "Giménez".

${ }^{31}$ Sentencia "Koenig".

${ }^{32}$ Sentencia "Koenig".
} 
Sobre este mismo tema, pero desde el ángulo que problematiza la realización de fumigaciones por fuera de lo estipulado legalmente, existe una resolución en que se pone de relieve una conjunción entre la prohibición decidida en torno a las fumigaciones aéreas y la adopción de medidas para mejor conocer la problemática que se plantea.

Se trata de la sentencia resuelta por el Tribunal Criminal $N^{\circ} 2$ de Mercedes de la Provincia de Buenos Aires, "Di Vicensi, Oscar Alberto c/ Delaunay, Jorge s/ amparo" resuelta el 2 de abril de $2008^{33}$. En este caso se presenta un amparo por parte de un vecino del Partido de Alberti a los fines de lograr se suspendan las fumigaciones aéreas por incumplimiento de las distancias mínimas legalmente establecidas conforme la Ley Provincial $\mathrm{N}^{\circ} 10.699 / 1998$ y su Decreto Reglamentario ${ }^{34}$.

La resolución estima que: "tomando en consideración el potencial riesgo para los bienes y salud de los pobladores de ese medio y el principio contenido en los arts. 41 de la Carta Magna Nacional, art. 28 de la Constitución de este Provincia, $1^{\circ}, 2^{\circ}, 3^{\circ}$ y cc de la ley $25.675,1^{\circ}$ de la ley 11.723 [...]. Hacer lugar parcialmente a la medida cautelar innovativa solicitada por Oscar Di Vicensi debiéndose anoticiar a Jorge Delaunay que deberá abstenerse en lo sucesivo de realizar por si o por terceros fumigaciones aéreas en los predios cultivados con soja que motivaron la presente acción....dispónese la realización por el término de 12 hs y por intermedio de la Asesoria Pericial Departamental de un Informe médico que ilustre al Tribunal sobre las consecuencias que puede acarrear a las personas y bienes -animales y vegetales-la fumigación con glifosato a la distancia efectuada por la accionada" 35

Así no sólo se plasma una decisión en cuanto al uso de agroquímicos sino que, además, se agrega el pedido de un informe que propende a conocer de manera más acabada las consecuencias que puede conllevar la exposición continuada al glifosato específicamente.

Una cuestión similar se plantea en el ya mencionado caso "Peralta". En éste, desde la primera instancia se califica la controversia y se articula la idea de riesgos con probabilidades, cuestión propia de las situaciones de raigambre

${ }^{33}$ Comentario a la sentencia en Esteves, Belén, Fallo comentado: "Di Vicensi, Oscar Alfredo c/ Delaunay, Jorge s/ amparo". Tribunal Criminal $N^{\circ} 2$ de Mercedes, provincia de Buenos Aires (02.04.2008), en La Ley. "Suplemento", "Derecho Ambiental", 15 (2008) 2.

${ }^{34}$ Este Decreto Reglamentario N499/2001 establece en su artículo 38 que: “Las empresas aplicadoras deberán operar a una distancia no menor de $2 \mathrm{Km}$. de centros poblados, no pudiendo sobrevolarlos aún después de haber agotado su carga. Se exceptúa de esta prohibición a las aplicaciones aéreas destinadas al control de plagas urbanas autorizadas especificamente por el Organismo Municipal competente, asi como los casos que establezcan los organismos oficiales. La misma deberá contar con la Receta Agronómica"

${ }^{35}$ Sentencia "Di Vicensi". 
preventiva. Sin perjuicio de ello, se declara: “Que, por cuanto, derechamente, estimo que, cuando menos, es fuerte o muy alta la probabilidad que el uso de agroquímicos -o los mismos, como se prefiera-, que se relacionan en la demanda o en el Ley $N^{\circ} 11.273$, es nocivo tanto para el medio ambiente como para la salud de las personas, en consecuencia. Y para llegar a tal conclusión, a mi modo de ver, concurren, al menos, tres elementos, esto es, a) el mismísimo documento de fs. 101 [...]; b) los informes acercados en la materia (cfr. los aludidos en el dictamen del Sr. Fiscal); y c) la cada vez más amplia toma de decisiones al respecto, tanto a nivel comunal como municipal u otras reparticiones, según antecedentes que se aportan al expediente. Todo claro está, sin perjuicio de agregar los testimonios, como más abajo se deslindan, de los que hay que rescatar -voy anticipando-los problemas de salud de los menores de nombre, en especial, y que no cabe descartar que aquellos no obedezcan a la aplicación de los agroquimicos en el modo afirmado en la pretensión actoral que, dicho sea de paso, no se trata de un vecino sino de varios, sin que pueda estimarse-de ninguna parte del proceso surge elemento que indique lo contrario-, lo hayan becho -al reclamo-, poniéndose de acuerdo y sólo para provocar perjuicio o procurar otras alternativas o beneficios" ${ }^{36}$, argumentos que conducen a hacer lugar al amparo impetrado.

Ahora bien, en la segunda instancia, el problema del riesgo se reinterpreta y se puntualiza en la cuestión controversial. En tal sentido, se esgrime que: "fácil resulta concluir que no contamos en relación a la toxicidad pregonada con una certeza cientifica absoluta. Ahora, tal ausencia ¿constituye un óbice para la toma de decisión en el presente, si de lo que en verdad se trata es de evitar daños a la salud? La respuesta que a mi juicio se impone es negativa; $y$, por tanto, me apresuro a señalar que la aplicación del principio precautorio realizado por el juez a quo es correcta, ya que el mismo invita a actuar antes de que se obtenga la prueba del riesgo real, hipótesis que se encuentra receptada jurisprudencialmente con nuestro derecho como argumento central a los fines de reconocer pretensiones ambientales" ${ }^{37}$.

Esta carencia de certeza conduce a confirmar la resolución del tribunal a quo a la vez que, en una aplicación procedimental del principio precautorio, indica la necesidad de profundizar el conocimiento sobre el tema. Así, resuelve otorgar un plazo de seis meses para que la Universidad Nacional del Litoral y el Ministerio de Agricultura, Ganadería, Industria y Comercio de la Provincia (actualmente Ministerio de la Producción) presenten un estudio en el que se estime el grado de toxicidad de los productos identificados y para que el Ministerio de Salud presente un análisis en los barrios comprometidos de

\footnotetext{
${ }^{36}$ Sentencia "Peralta" Primera instancia.

${ }^{37}$ Sentencia "Peralta" Segunda instancia.
} 
San Jorge para discernir si durante ese período las posibles afecciones denunciadas han disminuido o no. Los informes, una vez presentados, permitieron volver a decidir al juez de primera instancia que confirmó su resolución de mantener la prohibición de fumigar a 800 metros en caso de fumigaciones terrestres y 1.500 metros en el supuesto de fumigaciones aéreas, lo que fue nuevamente apelado y confirmado por la Cámara aunque modificando la prohibición para la fumigaciones terrestres de 800 a 500 metros.

Por último, y en torno al problema de las radiaciones no ionizantes emitidas por plantas transformadoras de energía eléctrica, se destaca la causa "Asociación Coordinadora de Usuarios, Consumidores y Contribuyentes c/ ENRE-EDESUR s/ cese de obra de cableado y traslado de sub-estación transformadora s/medida autosatisfactiva" resuelta en fecha 8 de julio de 2003 por la Sala II de la Cámara de Apelaciones de La Plata.

Aquí se propende al cese de una obra de cableado en vías de desarrollo y al traslado de la sub-estación transformadora. El tribunal estima que: "esta falta de certeza...no puede obstar a la adopción de medidas preventivas... la falta de certeza científica no puede utilizarse como razón para postergar la adopción de medidas eficaces para impedir la degradación del medio ambiente cuando haya peligro de un daño grave e irreversible"38.

Luego remite a una cantidad de estudios que se están produciendo sobre el tema: "se están efectuando activamente nuevas investigaciones frente a la posibilidad de que existan efectos nocivos sobre la salud por la exposición a largo plazo a niveles inferiores a los límites permitidos" ${ }^{\prime 3}$, que es seguida por una conclusión que esboza que la existencia actual de "incertidumbre en el conocimiento científico respecto de los efectos en la salud cuando la exposición aún a estos niveles resulta prolongada en el tiempo, lo cual es objeto de modernas y continuas evaluaciones cuyos resultados no estarán disponibles, según lo advierte la propia Organización Mundial de la Salud hasta dentro de unos años. Por tanto, esta falta de certeza respecto a una cuestión de la que, además, ya existen indicios importantes sobre sus efectos negativos no puede obstar a la adopción de medidas preventivas" ${ }^{\prime 4}$. La toma de medidas en este caso enhebra la suspensión de la obra de cableado de parte de la empresa demandada y la presentación de un informe "a fin de indicar las medidas que deberán poner en práctica para proteger a los residentes de Ezpeleta de los efectos potencialmente nocivos de los cables de alta tensión y de la subestación transformadora en cuestión" ${ }^{\prime 1}$.

Este conjunto de casos permiten canalizar algunas reflexiones sobre el

\footnotetext{
${ }^{38}$ Sentencia "Asociación Coordinadora".

${ }^{39}$ Sentencia "Asociación Coordinadora".

${ }^{40}$ Sentencia "Asociación Coordinadora".

${ }^{41}$ Sentencia "Asociación Coordinadora”.
} 
empleo del concepto de riesgo. Riesgo que ya no remitiría a aquello que puede ser probabilizado sino que, por el contrario, canaliza lo no completamente conocido aunque posible. Aquí se plantea un conflicto epistemológico dado que estas alusiones a lo incierto, lo posible, dejan en claro que se trabaja por fuera de los límites del programa del derecho de daños, construido sobre lo cierto y cognoscible.

Lo expuesto canaliza una serie de interrogantes. Entre ellos sobre la compatibilidad entre el programa del derecho de daños y este tipo de problemáticas así como sobre la reconstrucción de la controversia y cómo ésta puede viabilizar diferentes tipos de decisorios.

Una reflexión de este tenor configura una agenda aún no acabada dentro de la teoría jurídica que podría comenzar a efectuarse. En este camino adquieren relevancia los trabajos sobre casos judicializados. Hasta ahora se verificó una pléyade de decisiones en la aplicación del principio precautorio dentro del espectro de medidas viables que incursionan desde la toma de decisiones sobre el fondo del tema, la ordenación de medidas para gestionar los riesgos, la puesta en marcha de mecanismos que permitan conocer mejor las hipótesis llevadas ante la instancia judicial a los fines de decidir, o bien, la construcción de canales procedimentales para resolver.

Desde una postura constructivista sobre la producción de saberes, una estrategia de demarcación y clasificación de tipos de controversias estáticas aparece compleja ya que se trabaja con procesos de construcción social variables. Esto, sin embargo, no significa que no puedan delinearse algunas pautas generales para dar significado al principio precautorio ante casos en los que la posibilidad de daños graves aparece importante y grave.

En esta tarea podría proponerse el seguimiento de los pasos que a continuación se enumeran y que enfatizan en la cuestión controversial cuando se trata de decidir en torno a hipótesis de precaución, lo que debería ser articulado de manera insoslayable con cada conflictividad planteada: $i$ ) determinar los contornos de la controversia científica sobre los riesgos que informan la hipótesis sobre la que se debe decidir ${ }^{42}$. Esta labor implica poner en diálogo

${ }^{42}$ Esta tarea es fundamental y se ha sostenido en una multiplicidad de documentos referidos al principio. Verbigracia, "Una cierta forma de análisis cientifico es obligatoria; la mera fantasía o la especulación simplista no son suficientes para poner en marcha el PP. Los motivos de preocupación que pueden desencadenar el PP se limitan a los que son plausibles o cientificamente defendibles (o sea, no fácilmente refutables)": "Informe del grupo de expertos sobre el Principio de Precaución de la UNEsco" (2005), p. 13; " $\mathrm{La}$ condición previa y necesaria para recurrir al principio de precaución es una evaluación de los datos cientificos sobre los riesgos. Sin embargo, un elemento precede lógica y cronológicamente a esta evaluación: la determinación de los efectos potencialmente peligrosos que se derivan de un fenómeno. Para tener una mejor comprensión de estos efectos, resulta 
todas las esferas de producción de conocimiento disponibles, esto es, no sólo la controversia que pudiere desarrollarse al interior del 'parlamento científico' sino aquella que se detecta por fuera de éste y, en muchos casos, lo problematiza $\left.{ }^{43} ; i i\right)$ una vez efectuada esta primera operación y detectados los principales lineamientos de la controversia que informa la conflictividad llevada a la instancia jurisdiccional el paso siguiente consiste en canalizar medidas para reducir la incertidumbre arrojada por el ejercicio anterior hasta donde sea viable ${ }^{44}$. De hecho, en algunas hipótesis esta tarea no resulta posible y de allí el criterio de viabilidad en la tarea reductiva. En otros casos esta labor sí es factible y conduce a construir hipótesis sobre posibles daños que resulten razonables.

Lo expuesto permitiría canalizar una detección más clara de los posibles riesgos que atentan contra el ambiente y/o la salud humana de diferentes colectivos sociales lo que, en concomitancia, remite a la prueba del vínculo causal. Este tema constituye uno de los tópicos más complejos al momento de abordar situaciones de precaución, tal y como se desarrolla en el apartado siguiente.

necesario proceder a una evaluación cientifica": "Comunicación de la Comisión sobre el recurso al principio de precaución” (2000), p. 8.

${ }^{43}$ En este sentido, es relevante destacar la Pauta $4^{a}$ de las "Pautas para aplicar el principio de precaución a la conservación de la biodiversidad y la gestión de los recursos naturales" de The Precautionary Principle Project (iniciativa conjunta entre Flora \& Fauna Internacional, UICN, Resources África y TRAFFIC) que expresa: "Incluya a los actores clave y a los titulares de derechos en un proceso transparente de evaluación, toma de decisiones e implementación"; y la Pauta 5a que afirma: "Fundamente la toma de decisión en la mejor información disponible, incluyendo aquella relativa a acciones humanas que impulsan las amenazas, asi como el conocimiento indigena y tradicional". Por su parte el Informe de la UNESCO citado en la nota al pie anterior afirma que: "La ciencia para una politica que haga frente a la incertidumbre requiere nuevas formas transdisciplinarias de contacto y de integración (extensión dentro de la comunidad cientifica), por un lado, y nuevos contactos con los responsables de la elaboración de politicas, las organizaciones no gubernamentales, la industria, los medios de comunicación y el público (extensión al exterior de la comunidad cientifica), por otro, para hacer frente a los desafios del control de calidad en la evaluación de los riesgos complejos". Pág. 37.

${ }^{44}$ Esta idea de "obligación de investigar" es una de las reglas de la precaución. KouRILSKy, Philippe - VIney, Genevieve, Le principe de précaution. Rapport au Premier Ministre (Paris, Editions Odile Jacob, La documentation française, 1999). Implica, además, sortear la vieja idea que piensa el principio precautorio como "anticientífico": Noiville, Christine, Science, décision, action: trois remarques à propos du principe de précaution, en Petites Affiches, 11 (2004). 


\section{LA COMPLEJA TAREA DE REPENSAR LA RELACIÓN DE CAUSALIDAD}

En el conjunto de sentencias que hasta aquí estudiadas, aunque la cuestión de lo potencial en torno a riesgos aparece de manera habitual son menos numerosas las remisiones al tema de la causalidad de forma explícita, aunque, implícitamente, las decisiones abordadas han flexibilizado su funcionamiento más allá de la tesitura que se plantea vía el criterio de adecuación ${ }^{45}$.

Esta perspectiva ha sido ya tematizada por parte de la dogmática que afirma la necesidad de repensar este presupuesto a la luz, fundamentalmente, de problemáticas ambientales ${ }^{46}$. Se acuerda que en los casos de esta índole la causalidad debe ser repensada y flexibilizada en virtud de su propia raigambre lo que, en términos precautorios, se complejiza especialmente debido a la carencia de información acabada para delinear vínculos causales. Aquí las estrategias que se estiman respecto de la fijación de probabilidades se encontrarían también desbordadas.

Ello reedita la indagación sobre la idoneidad que debería poseer una condición para ser calificada como causa, en un ámbito en el que existen controversias que impiden la concretización de un vínculo causal claro.

El plano de la causalidad, que actualmente presenta un alto grado de opacidad, configura una de las agendas dentro del marco de la doctrina que se ocupa del tema ambiental y relativo a la salud lo que ha permitido delinear algunas propuestas. Éstas consisten en pensar regímenes de causalidad más adecuados para abordar temas vinculados a la cuestión ambiental. En tal sentido, se han esbozado una múltiple cantidad elaboraciones ${ }^{47}$.

En el caso específico de las hipótesis de precaución el problema se inscribe en la indeterminación causal. Este concepto de indeterminación posee antecedentes en el derecho de daños en términos de causalidad anónima -lo cual se analiza dentro del marco de la responsabilidad colectiva cuando se trata de una intervención disyunta o alternativa-, en la que el hecho parece

${ }^{45}$ Cabe señalar, por ejemplo, que el juez Enrique Müller refiere a la resolución adoptada en "San Jorge" como un caso de "causalidad compleja": Müller, Enrique, El perfil del juez ambiental. Sus facultades. La cuestión ambiental y el nuevo rol de la juricatura, en Revista de Derecho de Daños, 1 (2011).

${ }^{46}$ Besalú Parkinson, Aurora Responsabilidad por daño ambiental (Buenos Aires, Hammurabi, 2005); CAFFERATTA, Néstor, El principio de prevención en el derecho ambiental, en Revista de Derecho Ambiental, 10 (2004); y Responsabilidad por daño ambiental (Material Programa Naciones Unidas para el Medioambiente, 2009)

${ }^{47}$ Véase: ThibIerge, Catherine, Libres propos sur le droit de la responsabilité. Vers un élargissement de la fonction de la responsabilité civile? en Revue Trimestral de Droit Civile (Julliet-Septembre, 1999). 
poder atribuirse a una u otra persona pero sin poder probarse quien efectivamente lo ha causado ${ }^{48}$.

Es claro que existe una diferencia relevante con el tema que aquí se aborda debido a que lo 'anónimo' en estos últimos no refiere a la imposibilidad de probar la autoría del hecho dañoso, sino que la imposibilidad viene mediada por una controversia científica que impide entablar vínculos causales. Por tanto, la cuestión se podría esbozar mediante la idea de causalidad posible, ni siquiera aún probable dado que, a diferencia de las probabilidades que pueden establecerse ante riesgos cognoscibles aquí no existirían -al menos en principio- elementos para pensar en tales términos. Esto implica un giro epistemológico importante, dada la emergencia de un modo de conocer que problematiza la racionalidad científica. Racionalidad que, por otra parte, ha permeado la institucionalidad probatoria en el campo jurídico e informa en gran medida la determinación o no de causalidades.

Si bien es reiterada la afirmación sobre la necesidad de re-construir la teoría de la causa en casos controvertidos, es cierto también que tales reflexiones no se siguen de una construcción que pueda comenzar a edificar 'otra' teoría causal. Tales alusiones aparecen en la jurisprudencia lo que permite sostener la idea de una emergente identificación de la necesidad de "re-pensar" este tema con el objeto de orientar este tópico ante situaciones de precaución. Estos ejercicios posibilitan, además, iluminar cómo un tema puede ser postulado desde diversas ópticas y canalizar distintas argumentaciones.

En el caso "Asociación Coordinadora" la cuestión causal fue tematizada de modo explícito y asumió un espacio cardinal en la toma de decisiones tanto de primera como de segunda instancia.

El juez a quo rechazó la acción y sostuvo que: "[...] la falta de certeza acerca de los efectos negativos de los campos electromagnéticos sobre la salud humana...obsta a la vinculación causal entre las dolenciaspadecidaspor los habitantes de la localidad de Ezpeleta y el supuesto agente contaminador. Todo ello sin perjuicio del derecho de los actores de canalizar el reclamo de autos a través de un proceso de conocimiento que posibilite un mayor debate y prueba de la cuestión debatida y garantice el derecho de defensa de las partes involucradas [...]"49.

Ahora bien, en la resolución de Cámara la decisión cambia, se revoca la sentencia de primera instancia y se sostiene que: "resulta probado, con el

\footnotetext{
${ }^{48}$ Se suele separar la intervención disyunta/alternativa de la intervención grupal en razón de dos cuestiones prácticas: $i$ ) las eximentes que operarían en el segundo caso probando la no participación en el grupo; y ii) la existencia o no de solidaridad: LoRENZETTI, Ricardo, Responsabilidad colectiva, grupos y bienes colectivos, en La Ley Sección "Doctrina”, D (1996).

${ }^{49}$ Sentencia "Asociación Coordinadora".
} 
grado de certeza requerido en esta etapa procesal, los daños en el medio ambiente y, principalmente, en la salud y calidad de vida de los habitantes de la ciudad de Ezpeleta, Partido de Quilmes, generados por la exposición continua y prolongada a los campos electromagnéticos que produce la subestación Sobral y el cableado de alta tensión dispuesto, con un grado de peligro tal que reclama una urgente solución "[...]. En efecto, conforme surge del plano de la zona en que se ubica la mencionada planta transformadora y de los certificados médicos acompañados en autos, se observa que una importante porción de los vecinos que habitan sobre las calles aledañas con la subestación Sobral "[...] padecen, entre otras dolencias, de cáncer de colon, cáncer de mama, leucemia linfoblástica aguda entre otras dolencias -en este caso se trata de una menor de 16 añosvariadas afecciones psiquicas e hipertensivas, las cuales han provocado, en algunos casos, la muerte de los afectados" 50 .

De este modo, se deja claro que la interpretación sobre el funcionamiento de la relación causal en hipótesis no acabadamente conocidas canaliza perspectivas divergentes e, incluso, opuestas. Una primera muy edificada en torno al criterio de certeza y otra que transforma tal situación y permite la acogida de demandas que se fundan en posibles afectaciones graves al ambiente o a la salud aunque, en la gran mayoría de los casos, sin construir argumentaciones que de modo expreso remitan a la cuestión de la necesidad de consolidación de otros regímenes de causalidad y el 'cómo' de tales elaboraciones teóricas.

Sobre este último punto, sin embargo, aparecen algunas referencias que ponen de relieve una conceptuación heterogénea de la causalidad. Por ejemplo, y también sobre contaminación por radiaciones no ionizantes, se encuentra la sentencia "Defensoría”. Allí se expresa que: "el principio de precaución resulta aplicable cuando la existencia de una relación causal entre una determinada tecnología y un posible daño o perjuicio no ba sido aún cientificamente comprobada de modo pleno. Entonces, cuando una determinada actividad se plante como una amenaza para la salud bumana $o$ elmedioambiente, deben tomarse medidas precautorias aún cuando algunas relaciones de causa y efecto no se hayan probado cientificamente en su totalidad"51.

En sintonía con estas afirmaciones, en la sentencia "Giménez" se establece que: "En la materia que nos ocupa es frecuente que sólo una vez que el daño haya sido producido, puede establecerse el nexo causal entre la actividad responsable del mismo y este último. Por esta razón el Principio Precautorio lo que pretende es servir de fundamento legal para la adopción de medidas, aún cuando dicho nexo causal no esté debidamente acreditado; es decir cuando sobre una actividad o tecnología reine la incertidumbre respecto de

\footnotetext{
${ }^{50}$ Sentencia "Asociación Coordinadora".

${ }^{51}$ Sentencia "Defensoría”.
} 
la nocividad de su accionar y no haya todavía un daño a ella atribuible. Sin embargo, por la misma razón por la cual no resulta manifiesta la violación de derecho alguno, esto es la incertidumbre cientifica, siresulta manifiesto el riesgo que tal actividad trae aparejado sobre derechos tales como la salud, la vida y el ambiente sano y equilibrado. De este modo, la falta de certeza cientifica constituye un riesgo, una amenaza manifiesta en los términos del art. 43 de la $C N$, resultando plenamente procedente la invocación del Principio Precautorio como fundamento para la adopción de medidas en la vía excepcional del amparo"s2

Estas argumentaciones articulan el vínculo causal con la incerteza científica que subyace al principio precautorio, lo que puede visibilizarse como expresión de una emergente necesidad de abordaje sobre este presupuesto que, largamente consolidado mediante la edificación de diferentes teorías, hoy parece no poder asignar adecuada respuesta ante casos controvertidos. Si bien se ha sostenido que la causalidad frente al principio de precaución no significa más que una relajación del umbral de convicción que se requiere para determinar causalidades ${ }^{53}$, lo cierto es que aparece relevante intentar iluminar qué canaliza el cambio epistemológico que se introduce en relación a las ciencias para pensar su revisión a la luz de una racionalidad científica cuestionada y de saberes proliferando desde diferentes ámbitos.

La tarea se presenta ardua y dificultosa. Actualmente existe un cuestionamiento importante respecto del funcionamiento de las ciencias como espacio para la producción de saberes desde la 'imagen' que se ha consolidado modernamente y que canalizó una importante 'deferencia' de parte del derecho. Esta "actitud" se visualiza en un repertorio de aristas que campean la determinación de causalidades así como, también, en el concepto del daño resarcible y de los riesgos probables que son aquellos con los que aún se puede laborar en el marco del programa del derecho de daños. Ahora, en la intersección con el derecho ambiental, la cuestión se complejiza dado que el principio precautorio allí inserto pone de relieve esta otra "imagen" del funcionamiento de las ciencias que se corresponde en mejor medida con su funcionamiento interno, de larga data, lo que ha sido visibilizado por parte de los estudios sociales de las ciencias.

Así, en un momento en que se yuxtaponen diferentes paradigmas para la gestión de riesgos que podría ser calificado como de "transición" hacia una emergente decisión precautoria la cuestión de la causalidad no podría

${ }^{52}$ Sentencia "Giménez".

53 "la aplicación del principio precautorio no es más que una relajación en el umbral de convicción requerido [...] es dudoso que, por sí, pueda considerarse una modificación significativa en aspectos conceptuales básicos de la teoria de la causalidad jurídica en el derecho de daños": ACIARRI, Hugo La relación de causalidad y las funciones del derecho de daños (Buenos Aires, Abeledo Perrot, 2009). 
ser soslayada. Por el contrario, podría pensarse en algunos lineamientos fundamentales para su abordaje.

En ese sentido, se estima importante - dada la casuística que impregna la aplicación del principio que nos ocupa-, pautar una serie de cuestiones a tener en cuenta para el intento por establecer causalidades lo que retoma, en buena medida, lo expresado en torno al riesgo.

La cuestión aquí enfoca especialmente en la existencia o no de saberes y datos específicos sobre el conflicto llevado a la sede jurisdiccional en la tarea de responder si efectivamente en el caso específico ha habido relación de causa-efecto plausible. Como consecuencia, se estima relevante su producción en caso que los mismos no se encontraran disponibles y fuera factible su realización de parte de organismos competentes para ello, ya sea dentro del mismo proceso judicial mediante pericias y dictámenes técnicos o articulando con otras instituciones competentes.

Cuando se hizo referencia al riesgo en el apartado anterior se estipuló la trascendencia de demarcar convenientemente la controversia científica y los aportes provenientes de otros espacios de producción de saberes. Este paso, por supuesto, es insoslayable para la determinación causal. Es decir para intentar dotar de respuesta a cómo vincular riesgos posibles identificados con determinado agente presuntamente contaminante. Para ello, nuevamente, es conveniente reconstruir para el caso concreto la controversia que lo informa desde el nuevo paradigma emergente sobre las ciencias, lo que conlleva no sólo verificar e indagar en el ámbito científico sino, también, fuera del mismo y valorar las informaciones, datos, etcétera, que provengan de profesionales de la salud, ejercicios de epidemiología popular, organizaciones no gubernamentales, entre otros. Asimismo, se exige verificar la excelencia de los expertos que informan en el caso, su independencia o vinculación con la problemática que permita obtener mejores herramientas para la valoración de la información que brinde en el marco de la reconstrucción efectuada.

Por otra parte, la implementación de medidas para reducir la incertidumbre lo más posible también se consolida como cardinal no sólo para establecer qué riesgos se correrían sino, también, para la determinación de la relación de causalidad. De hecho, es este un elemento fundamental dado que permite valorar la controversia con el grado más acabado posible de conocimientos.

En este marco se torna complejo pensar en posibilidades a la manera de probabilidades, asignando un determinado porcentual que permitiría establecer o no un vínculo causal. Aparece más adecuado pensar la causalidad en términos de posibilidad 'plausible'. Esta plausibilidad estará informada y mediada por las operaciones anteriormente descriptas que, al esclarecer los márgenes de la controversia y -cuando sea factible- indagar en el problema concreto en términos epidemiológicos y toxicológicos canalizaría diferentes 
tipos de decisiones judiciales de índole proporcional según las características de cada caso y revisable dada la propia naturaleza inestable de los conocimientos disponibles.

\section{REFLEXIONES FINALES}

Las resoluciones abordadas aquí permiten visibilizar ciertas modalizaciones tanto sobre las vías de tutela inhibitoria, como respecto de la cuestión de daños y riesgos y de la relación causal en un ejercicio que podría ser presentado como sub-paradigmático, reformista.

En primer lugar, se trabaja sobre el tema de las vías de tutela inhibitoria utilizadas. Existe aquí una numerosa cantidad de sentencias en las que se verifican morigeraciones de los requisitos de funcionamiento de algunos mecanismos, en particular, de aquellos que hacen a la certeza como condición de procedencia. Las controversias son presentadas en términos tales que permiten argumentar que su entidad es lo suficientemente relevante como para ser atendida por medio de estas vías, a lo que se suma la inexistencia de otras herramientas especialmente pensadas para trabajar con hipótesis de esta naturaleza. La cuestión se encuentra planteada. Desde una estrategia sub-paradigmática, reformista, los supuestos aquí atendidos permiten poner en movimiento las herramientas seleccionadas. Desde otro tipo de estrategia, la cuestión canalizaría una agenda no sólo de reflexión en torno a los conflictos epistemológicos que se presentan al interior del derecho de daños y una consecuente tarea de demarcación sino, por el contrario, una labor de creación institucional acompañada de una teoría jurídica adecuada.

Este mismo razonamiento se puede efectuar en torno al funcionamiento del concepto de riesgos. Aquí aparece una multiplicidad de alusiones en términos de posibilidad, eventualidad, no actualidad, controversia e incerteza que requieren pautar algunas operaciones para, luego, adoptar decisiones en torno a la hipótesis planteada. En tal sentido se propusieron algunos pasos a los efectos de comenzar a pensar el modo de abordaje de estos casos tanto desde el ángulo de los riesgos como de la relación causal. Esta última se tematiza en las sentencias, aunque de manera más tangencial, visibilizando el problema para su funcionamiento y articulando nuevas formas de pensarla a partir del principio de precaución.

La tarea que impone pensar la cuestión de daños, riesgos y causalidad en torno a la controversia científica, sin bien comienza a aparecer, es aún incipiente y puede apoyarse en los supuestos en que se ha planteado a los efectos de revisarlos para proponer una serie de operaciones que canalicen la aplicación del principio y permitan un mejor funcionamiento del mismo. Estas tareas necesariamente deben delinear los contornos de la controversia, 
intentar profundizar en la medida de lo posible el conocimiento existente y adoptar una serie de decisiones que se articularán de manera directa con la entidad que puede atribuirse a los riesgos posibles problematizados en el marco de una relación causal plausible. Esta última articulada de manera directa con este ejercicio de reconstrucción bajo una perspectiva de "ecología de saberes" ${ }^{54}$ lo suficientemente amplia pero, a la vez, juiciosa que conduzca a decisiones proporcionales en atención a los casos concretos.

Podría pensarse que estas reflexiones resumen las agendas abiertas en el plano de la jurisdicción respecto del principio precautorio en su articulación con el andamiaje del derecho de daños que, largamente, se ha ocupado del problema de los riesgos en el campo legal argentino.

\section{BiBLIOGRAFÍA}

Andrada, Alejandro - Hernández, Carlos Soja, principio precautorio y agroquímicos, en Revista de Derecho de Daños, 1 (2011).

BECK, Ulrich La sociedad del riesgo global (Barcelona, Siglo XXI, 2002).

BECK, Ulrich La sociedad del riesgo mundial (Barcelona, Paidos, 2007).

BECK, Ulrich La sociedad del riesgo. Hacia una nueva modernidad (Barcelona, Paidos, 1998).

Besalú Parkinson, Aurora Responsabilidad por daño ambiental (Buenos Aires, Hammurabi, 2005).

Bestani de SEguir, Adriana Elprincipio deprecaución en la jurisprudencia de la Suprema Corte de Justicia de la Nación, en Jurisprudencia Argentina, “Doctrina”, Dic. 2011.

Bestani de Seguir, Adriana Uso (¿y abuso?) jurisprudencial del principio de precaución en la tutela procesal ambiental: el rol del juez, reglas probatorias e incertidumbre cientifica en Revista de Derecho Ambiental, 17 (2010).

CAFFeratTa, Néstor El principio de prevención en el derecho ambiental en Revista de Derecho Ambiental, 11 (2004).

Cafferatta, Néstor Responsabilidad por daño ambiental (Material Programa Naciones Unidas para el Medioambiente, 2009).

Cafferatta, Néstor - Goldemberg, Isidoro El principio de precaución JA 6-IV (2002).

${ }^{54} \mathrm{La}$ expresión ecología de saberes refiere a que, ante la existencia de diferentes intervenciones en la realidad que pueden fundarse en distintos sistemas de conocimiento, la preferencia en relación a estos últimos debe ser otorgada a aquel que permita garantizar la mayor participación de los grupos sociales involucrados en el diseño, ejecución y control y en los beneficios de la intervención. En virtud de ello se considera que las formas de ignorancia son tan heterogéneas como las de conocimiento y la idea que subyace a la ecología de saberes es la de prudencia, en tanto aprendizaje de los otros conocimientos sin olvidar el propio; así: SANTos, Boaventura de Sousa, Para descolonizar Occidente. Más allá del pensamiento abismal (Buenos Aires, ClACso-Prometeo, 2010). 
DRNAS DE ClÉMENT, Zlata Elprincipio de precaución ambiental.La práctica argentina (Córdoba, Lerner, 2007).

Embid Tello, Antonio Eduardo Elprincipio deprecaución, en Santamaría Pastor, J. y otros, Los principios jurídicos del derecho administrativo (Madrid, La Ley, 2010.

Esteves, Belén Fallo comentado: "Di Vicensi, Oscar Alfredo c/Delaunay, Jorges/amparo". Tribunal Criminal $N^{\circ} 2$ de Mercedes, provincia de Buenos Aires (02.04.2008) en La Ley, “Suplemento”, "Derecho ambiental”, 15 (2008) 2.

Ewald, François. L'État de précaution en Rapport public du Conseil d'Etat. Jurisprudence et avis de 2004, en Responsabilité et socialisation du risque. La Documentation Française. Études et documents, 56 (2004).

Hermitte, Marie-Angèle La fondation juridique d'une société des sciences et des techniques par les crises et les risques en BuRTON, C, y otros, Face au risque (Saint-Rémy-deProvence, L'Equinoxe, 2007).

Kourilsky, Philippe - VIney, Genevieve Leprincipe deprécaution. Rapport au Premier Ministre (Paris, Editions Odile Jacob, La documentation française, 1999).

LATOUR, Bruno Politiques de la nature. Comment faire entrer les sciences en démocratie (Paris, La Decouverte, 2004).

Lorenzetti, Pablo Agroquimicos versus principio precautorio ¿una opción trágica? en Revista de Derecho Ambiental, 27 (2011)

LORENZETTI, Ricardo Las normas fundamentales de derecho privado (Santa Fe, Rubinzal Culzoni, 1995).

LoRENZETTI, Ricardo Responsabilidad colectiva, grupos y bienes colectivos en La Ley Sección Doctrina D (1996).

Marchiaro, Enrique Soja y derecho municipal ambiental. Potestades y limites jurídicos de los municipios argentinos frente al monocultivo y los agroquimicos (Buenos Aires, Ediar, 2011).

MüLLER, Enrique El perfil del juez ambiental. Sus facultades. La cuestión ambiental y el nuevo rol de la juricatura, en Revista de Derecho de Daños ,1 (2011).

Noiville, Christine. Science, décision, action: trois remarques à propos du principe de précaution, en Petites Affiches, 11 (2004).

Santos, Boaventura de Sousa Crítica de la razón indolente. Contra el desperdicio de la experiencia (Bilbao, Desclée de Brouwer, 2003).

Santos, Boaventura de Sousa Para descolonizar Occidente. Más allá del pensamiento abismal (Buenos Aires, CLACSO - Prometeo Libros, 2010).

Sozzo, Gonzalo La prevención del daño (ensayo desde la mirada de las vias periféricas), en Revista de Derecho Privado y Comunitario, 1 (2008).

Sozzo, Gonzalo Las victimas del daño ambiental (la construcción de una nueva subjetividad) en Revista de Derecho de Daños, 1 (2011).

Sozzo, Gonzalo - Berros, María Valeria, Principio precautorio, en Revista de Responsabilidad Civily Seguros. La Ley III, 28, (2011).

Sozzo, Gonzalo - Berros, María Valeria, Una agenda para el principio precautorio, en Revista Critica de Derecho Privado La Ley Uruguay, 6 (2009).

Thibierge, Catherine, Libres propos sur le droit de la responsabilité. Vers un élargissement de la fonction de la responsabilité civile? en Revue Trimestral de Droit Civile (Julliet-Septembre 1999). 
